\title{
Prevention of ventilator-associated pneumonia
}

\author{
Arthur CW Lau *, HM So, SL Tang, Alwin Yeung, SM Lam, WW Yan; Hong Kong East Cluster Task Force \\ on Prevention of Ventilator-associated Pneumonia in Critical Care Areas
}

\begin{abstract}
A B S T R A C T
Ventilator-associated pneumonia is the commonest, yet mostly preventable, infection in mechanically ventilated patients. Successful control of ventilatorassociated pneumonia can save hospitalisation cost, and is possible by using a multidisciplinary clinical and administrative approach. The ventilatorassociated pneumonia rate should be expressed as the number of ventilator-associated pneumonia days per 1000 ventilator days to take into account the device-utilisation duration for meaningful comparison. Various strategies address the issue, including general infection control measures, body positioning, intubation and mechanical ventilation, oral and gastro-intestinal tract, endotracheal tube, airway pressure, cuff pressure, selective digestive and/or oropharyngeal decontamination, and probiotic or early antibiotic treatment, as well as overall administration at a policy level. The rationale and controversy of these approaches are discussed
\end{abstract}

treating mechanically ventilated patients should have a ventilator-associated pneumonia prevention protocol in place, and ventilator-associated pneumonia should be seriously considered as a key performance indicator in local intensive care units.

Hong Kong Med J 2015;21:61-8

DOI: $10.12809 / \mathrm{hkmj} 144367$

${ }^{1}$ ACW Lau * FHKAM (Medicine)

${ }^{1}$ HM So, FHKAN (Critical Care)

${ }^{2}$ SL Tang, BSc (Nursing)

${ }^{2}$ A Yeung, FHKAM (Medicine)

${ }^{1}$ SM Lam, FHKAM (Medicine)

${ }^{1}$ WW Yan, FHKAM (Medicine)

for the Hong Kong East Cluster (HKEC) Task Force on Prevention of

Ventilator-associated Pneumonia (VAP) in Critical Care Areas

Department of Intensive Care, Pamela Youde Nethersole Eastern Hospital, Chai Wan, Hong Kong

2 Cardiac and Intensive Care Unit, Ruttonjee Hospital, Wanchai, Hong Kong

* Corresponding author: laucw3@ha.org.hk

\section{Introduction}

Ventilator-associated pneumonia (VAP) is the commonest, yet mostly preventable, infection in mechanically ventilated patients. It contributes to increased morbidity, mortality, and total hospitalisation cost. The estimated overall attributable mortality of VAP was $13 \%,{ }^{1}$ and $52 \%$ of VAP was preventable. ${ }^{2}$ The VAP rate should be expressed as the number of VAP days per 1000 ventilator days to take into account the deviceutilisation duration for meaningful comparison. From the reports of the National Health and Safety Network (NHSN) of the US Centers for Disease Control and Prevention (CDC), ${ }^{3}$ a decreasing trend for VAP has been noted in recent years. For example, from 2002 to 2012, for a mixed medicalsurgical intensive care unit (ICU), the rate decreased from 5.1 to 0.9 days per 1000 ventilator days. The highest rates were reported for trauma (from 15.2 to 3.6 days) and burns (from 12.0 to 4.4 days) centres, while neurological and neurosurgical units reported intermediate rates (around 2 to 4 days). European rates are mostly higher, even if the same prevention strategies are used, and some possible reasons are explained below. ${ }^{4}$

Unlike many other conditions for which definitive diagnoses can be made pre-mortem, the gold standard of VAP diagnosis can only be made post-mortem. Clinicians diagnose VAP by radiology, signs and symptoms, with various methods of non-invasive and invasive microbiology sampling (tracheal aspirate, directed or blind broncho-alveolar lavage, protected specimen brush for qualitative and/or quantitative culture), and histology. However, when clinical criteria with microbiology were compared with autopsy findings, both the sensitivity and specificity were approximately $70 \%{ }^{5}$ Moreover, there has been no convincing evidence that qualitative culture of non-invasive samples, when compared with quantitative culture of invasive samples, produced any significant differences in clinical outcomes. ${ }^{6}$ In a survey of 27 ICUs of nine European countries, bronchoscopy was performed only in $23.3 \%$ of episodes of nosocomial pneumonia. ${ }^{7}$ Bronchoscopy might be considered more for immunocompromised hosts, both for detection of atypical organisms (if any) and to exclude infection.

The definition of VAP is therefore inherently subjective and, hence, contentious. The criteria used, interobserver variability, and subjectivity in chest $\mathrm{X}$-ray interpretation affect the VAP rates by almost two-fold. ${ }^{8,9}$ All these factors influence findings 


\section{呼吸機相關性肺炎的預防}

劉俊穎、蘇杏梅、鄧瑞蘭、楊維德、林倩雯、殷榮華； 香港醫院管理局香港東聯網監控呼吸機相關肺炎團隊

呼吸機相關性肺炎 (VAP) 是機械通氣患者最常見的感染, 但大多是 可以預防的。使用跨學科的臨床和管理方法可以成功控制這種感染， 繼而減省住院開支。要計算VAP發生率必須考慮到使用呼吸機的日 數, 即應以每 1000 個通氣日發生的VAP日數來計算, 這樣的比較才是 有意義的。此外, 可嘗試採用不同的策略防止VAP發生, 包括一般的 感染控制措施、病人的身體定位、氣管插管和機械通氣、口腔和胃腸 道、氣管內管、氣道壓力、內插管氣囊壓力、選擇性消化和/或口咽去 污、益生菌或早期抗生素治療, 以及在政策層面上的整體管理。本文 會討論這些方法的基本原理和當中的爭議。筆者認為所有處理機械通 氣患者的單位都應該設有一個預防VAP方案, 而本地的深切治療部門 也應認真考慮把VAP列為一項關鍵績效指標。 in preventive trials and hamper comparisons. For surveillance purposes, most institutions use the surveillance definitions of radiology/signs/ symptoms to monitor the rates. Commonly used surveillance definitions are those of the American Thoracic Society and Infectious Diseases Society of America (ATS/IDSA) ${ }^{10}$ and the CDC NHSN. The two sets of definitions are similar; the notable difference being that the ATS/IDSA guidelines exclude pneumonias occurring in the first 48 hours after intubation, whereas the CDC NHSN definition includes pneumonias in the first 48 hours; therefore, using the latter definition will result in a higher VAP incidence.

In an attempt to overcome the VAP definition's inherent subjectivity, in 2014, the CDC NHSN started surveillance using the Ventilator-Associated Event protocol, ${ }^{11}$ under which a ventilator-associated condition (VAC) is defined if there are at least 2 days of stable or decreasing ventilator settings (positive end-expiratory pressure [PEEP] and fraction of inspired oxygen) followed by consistently higher settings for at least 2 days. The sensitivity of the VAC criteria for the detection of VAP was only $25.9 \% .^{12}$ When further microbiological and invasive techniques are employed, a VAC can be further classified into an infection-related VAC, and possible VAP. This modification enables greater objectivity and facilitates automated electronic capture, but captures changes due not only to VAP.

\section{Pathophysiology and its implications for prevention strategies}

In terms of pathophysiology, VAP is a misnomer because its occurrence is not related to the ventilator per se, but to the presence of the endotracheal tube (ETT). The ETT allows direct access to the lower respiratory tract, impairing the cough reflex and mucociliary clearance, but provides incomplete sealing to secretions above the cuff. Microaspiration (of materials from oropharyngeal cavities, sinuses, gastro-intestinal tract) and biofilm formation are the two most important mechanisms in VAP development, while inhalation, bacteraemia and haematogenous spread play smaller roles. Molecular analysis showed that most VAP patients had the same bacteria with the same sequencing in their oral cavities as in their lungs, and there were even pathogens found in the lungs that could not be detected by conventional culture-based methods. ${ }^{13}$ Types of bacteria vary with the time of onset; in earlyonset VAP, they are commonly Enterobacteriaceae, Candida albicans and Staphylococcus aureus, ${ }^{14}$ while in late-onset VAP, they are Pseudomonas aeruginosa, Klebsiella pneumoniae, and Escherichia coli.

\section{Evolution of prevention strategies}

No single strategy is sufficient to prevent VAP, and several approaches are necessary. The most widely practised and well-known set of strategies is the Ventilator Bundle developed by the Institute for Healthcare Improvement (IHI) in 2001. ${ }^{15}$ The Ventilator Bundle is often mislabelled as the VAP Bundle, and its original aim was to improve better ventilator care overall, and not VAP alone, although its practice does reduce the VAP rate by $45 \% .^{15}$ The components of the Ventilator Bundle have now become the core of VAP prevention: (1) elevation of the head of bed to between $30^{\circ}$ and $45^{\circ}$; (2) daily 'sedative interruption' and daily assessment of readiness to be extubated; (3) peptic ulcer disease prophylaxis; (4) deep venous thrombosis prophylaxis (unless contra-indicated); and (5) daily oral care with chlorhexidine. It is practice of the whole 'bundle' that decreases VAP, not just the individual components. Some components are not directly related to VAP, namely, deep venous thrombosis and peptic ulcer disease prophylaxis. Although specific data on VAP were not available, in general, the risk of hospital-acquired pneumonia increased when acid-suppressant medications were used. There was a slight trend for reduced VAP with sucralfate compared with a histamine 2 receptor antagonist, and proton pump inhibitors may be related to a higher rate of VAP. ${ }^{16}$ Therefore, acid-suppressant medications should not be overused. In Hong Kong, the Centre for Health Protection of the Department of Health promulgated a set of recommendations of VAP prevention in $2010 .{ }^{17}$ In this article, we review the latest literature regarding VAP prevention, and the strategies are summarised in the Table. The rationale and controversy are elaborated in the following discussion. 
TABLE. Ventilator-associated pneumonia prevention strategies

Rationale and controversy behind some of the strategies are elaborated in the text. Strategies that have been suggested in the literature, but are not yet widely practised and/or require further research are listed in italics

\begin{tabular}{|c|c|}
\hline Category & Strategies \\
\hline \multicolumn{2}{|l|}{ Clinical } \\
\hline General & $\begin{array}{l}\text { Standard precautions of infection control } \\
\text { Hand hygiene, observe WHO 5-moment hand hygiene protocol }{ }^{\star} \\
\text { Regular change of ventilator tubing not more frequent than once a week, unless visibly soiled } \\
\text { Drainage of fluid condensate, especially during transport or position change } \\
\text { DVT prophylaxis (as a component of IHI VAP bundle) } \\
\text { Environment cleansing } \\
\text { Regular microbiological surveillance }\end{array}$ \\
\hline Body positioning & $\begin{array}{l}\text { Semi-recumbent positioning, ie raise head of bed to } 30^{\circ}-45^{\circ} \text { to the horizontal } \\
\text { Use devices for angle monitoring } \\
\text { Continuous lateral rotation therapy (kinetic bed therapy) }\end{array}$ \\
\hline $\begin{array}{l}\text { Intubation and mechanical } \\
\text { ventilation }\end{array}$ & $\begin{array}{l}\text { Aseptic technique during intubation and tracheostomy tube change } \\
\text { Orotracheal route of intubation preferred for less sinusitis and VAP } \\
\text { Prevention of self-extubation, and also re-intubation } \\
\text { Use NIV as much as possible for evidence-based indications } \\
\text { Use NIV for early weaning, especially for COPD } \\
\text { Daily sedation holiday } \\
\text { Assess fitness for extubation daily, and have weaning protocols } \\
\text { Avoid prolonged use of paralytics } \\
\text { Nurse-led sedation and weaning }\end{array}$ \\
\hline Oral and gastro-intestinal tract & $\begin{array}{l}\text { Regular oral care with } 0.12 \%-2.0 \% \text { chlorhexidine } \\
\text { Consider continuous oral suction } \\
\text { Confirm appropriate gastric tube position before feeding } \\
\text { Gastrostomy feeding for longer-term feeding } \\
\text { Avoid large-bore gastric tube } \\
\text { Stress ulcer prophylaxis, a component of IHI VAP bundle, but avoid overuse of acid suppressants } \\
\text { Avoid early enteral feeding } \\
\text { Consider post-pyloric feeding }\end{array}$ \\
\hline Endotracheal tube & $\begin{array}{l}\text { Consider use of novel ETT: subglottic secretion drainage, especially for patients likely to be ventilated for } \\
>48 \text { hours, taper-shaped cuff (eg TaperGuard), polyurethane (eg Microcuff instead of PVC cuff material } \\
\text { Consider use of silver-coated ETT for biofilm prevention } \\
\text { Consider mechanical removal of biofilm }\end{array}$ \\
\hline Airway pressure & $\begin{array}{l}\text { Maintenance of PEEP during mechanical ventilation, avoid zero PEEP } \\
\text { Avoid routine suction and use the lowest suction force necessary for the shortest duration } \\
\text { Minimise airway disconnection as much as possible } \\
\text { Avoid frequent patient transport }\end{array}$ \\
\hline Cuff pressure & $\begin{array}{l}\text { Regular maintenance of cuff pressure of } 20-30 \mathrm{~cm} \mathrm{H}_{2} \mathrm{O} \text {, better with an automated cuff pressure } \\
\text { maintenance device than manual device }\end{array}$ \\
\hline $\begin{array}{l}\text { SDD, SOD, and probiotic or early } \\
\text { antibiotic treatment }\end{array}$ & $\begin{array}{l}\text { Consider selective oral decontamination } \\
\text { Consider selective digestive tract decontamination } \\
\text { Consider early antibiotic treatment for ventilator-associated tracheobronchitis }\end{array}$ \\
\hline
\end{tabular}

\section{Administrative}

Internal

VAP-prevention protocol in place

Regular documentation of VAP rate and benchmarking with international data

Regular audits on compliance with VAP-prevention strategies

Set VAP as regular item in business meeting for discussion, review every VAP case

Promulgate VAP rate and prevention strategies to all staff through various channels

Include VAP in orientation of new staff, and update existing staff regularly

External

Liaison with other departments for promotion of VAP-prevention practice

Promote good practice on websites, newsletters, medical journals, and symposia

Set up Coordination Task Force at hospital, cluster and ICU Central Organising Committee

Promote VAP surveillance as a key performance indicator in all ICUs

Continuous improvement

Continual literature update, research, and modifications of existing strategies

Cost-effectiveness analysis of the whole Ventilator Bundle

Explore the merits of ventilator-associated events by automated electronic capture

Abbreviations: COPD = chronic obstructive pulmonary disease; $\mathrm{DVT}=$ deep venous thrombosis; $\mathrm{ETT}=$ endotracheal tube; $\mathrm{ICU}=$ intensive care unit; IHI = Institute for Healthcare Improvement; NIV = non-invasive ventilation; PEEP = positive end-expiratory pressure; PVC = polyvinyl chloride; SDD = selective digestive decontamination; SOD = selective oropharyngeal decontamination; VAP = ventilator-associated pneumonia; WHO = World Health Organization

* The five moments include (I) before touching a patient, (2) before clean/aseptic procedure, (3) after body fluid exposure risk, (4) after touching a patient, and (5) after touching patient surroundings 


\section{Prevention strategies}

\section{Clinical strategies}

\section{General}

General principles of infection control should be followed. Ventilator tubing should not be changed more frequently than every 1 week unless it is visibly soiled. In an early prospective randomised trial of 447 patients, decreasing the frequency of ventilator circuit changes from 3 times to once per week had no adverse effect on the overall rate of VAP. ${ }^{18}$ Subsequent trials also showed that circuit change intervals of 7 and 30 days had even lower risks for VAP than 2-day intervals. ${ }^{19}$ There was evidence that chlorhexidine bathing and hand hygiene compliance reduced global and specific infection rates, including VAP. ${ }^{20}$ A protocol for microbiological surveillance could be considered to aid in selection of empirical therapy.

\section{Body positioning}

The semi-recumbent position $\left(30^{\circ}-45^{\circ}\right.$ to the horizontal) is widely practised as one of the components of the IHI Ventilator Bundle, but which was based on only one randomised study with a non-intention-to-treat protocol of 86 mechanically ventilated patients, comparing the supine and semirecumbent positions, in which the VAP rates were $34 \%$ and $8 \%$, respectively. ${ }^{21}$ Subsequent studies were not able to reproduce these results, and found that a $45^{\circ}$ position was difficult to maintain, and the mean angle achievable was only $28^{\circ}$. It has been suggested that avoidance of the supine position was beneficial as, while the semi-recumbent position might reduce gastro-oropharyngeal aspiration, the effect of gravity increases hydrostatic pressure of secretions pooled above the cuff. Recent animal studies found that mucus flow reversed towards the lungs in the semi-recumbent position, but drained out in the horizontal position. In human beings, the trachea/ ETT axis is below the horizontal in the lateral Trendelenburg position (ie lying lateral, at $5^{\circ}-10^{\circ}$ below the horizontal). The Gravity VAP-Trial, ${ }^{22}$ an international randomised controlled trial (RCT) aiming at enrolment of 800 patients, is ongoing to compare the efficacy and safety of the two body positions, namely, the lateral Trendelenburg versus the semi-recumbent positions, in reducing the incidence of VAP. The estimated study completion date is December 2016. Continuous lateral rotation therapy, or kinetic bed therapy, ie lateral rotation of patient to $\geq 40^{\circ}$ on one side (and $80^{\circ}$ total arc) using specially designed beds, has been reported to reduce VAP, but was associated with other side-effects such as intolerance to rotation, unplanned extubation, loss of vascular access, and arrhythmias. ${ }^{23}$

\section{Intubation and mechanical ventilation}

Non-invasive ventilation (NIV) should be used to avoid the need for invasive ventilation and also shorten its duration. Non-invasive ventilation is particularly beneficial in chronic obstructive pulmonary disease (COPD), immunocompromised patients, and acute pulmonary oedema, and it allows early weaning from invasive ventilation in COPD. Summary estimates from 16 trials of moderateto-good quality that included predominantly participants with COPD suggested that a weaning strategy that included NIV might reduce mortality and VAP rates without increasing the risk of weaning failure or reintubation. ${ }^{24}$

In a RCT of 128 adult mechanically ventilated patients, daily interruption of sedation resulted in a highly significant reduction in time spent on mechanical ventilation..$^{25}$ The same authors also showed in the Awakening and Breathing Controlled trial that paired daily spontaneous awakening tests (ie interruption of sedatives) with daily spontaneous breathing tests resulted in better outcomes for mechanically ventilated patients. ${ }^{26}$ Although there is persistent concern of increased complications with this practice such as self-extubation, subsequent study found that this was not the case. A nurseimplemented sedation protocol has been shown to decrease VAP. ${ }^{27}$ Our ICU is also performing a nurseled early weaning trial to aim at shortening the intubation period.

\section{Oral and gastro-intestinal tract}

Using chlorhexidine mouth rinse or gel as part of oral hygiene care, compared with placebo or usual care, was associated with a reduction in VAP, with a number needed to treat of 15 (95\% confidence interval, 10-34). ${ }^{28}$ There is no consensus for the best practice for oral hygiene care. The optimal concentration of chlorhexidine solution to use is not known. Chlorhexidine has been studied in two strengths: $0.12 \%$ and $0.2 \%$, and the US Food and Drug Administration recommends $0.12 \%$ oral chlorhexidine for use as mouth rinse. There is no evidence that the following is necessarily better than using chlorhexidine alone: addition of manual or powered tooth brushing, using Listerine (Johnson \& Johnson Healthcare Products, New Brunswick [NJ], US), sodium bicarbonate oral rinses, or use of povidone-iodine solution. Povidone-iodine seemed to increase the rate of acute respiratory distress syndrome. ${ }^{29} \mathrm{~A}$ local study showed that continuous clearance of oral secretion by the saliva ejector might reduce the rate of VAP, decreasing the duration of mechanical ventilation, and shortening the duration of stay of patients in the ICU. ${ }^{30}$ Although gastroesophageal aspiration is implicated in VAP development, in an intention-to-treat study of 449 patients on mechanical ventilation, the absence of gastric volume monitoring was not inferior to routine residual gastric volume monitoring in terms 
of development of VAP $(16.7 \%$ in the intervention group and $15.8 \%$ in the control group), nor were there any significant between-group differences in other ICU-acquired infections, mechanical ventilation duration, ICU stay duration, or mortality. ${ }^{31}$ There were more VAPs with early enteral feeding, and less with post-pyloric feeding. Further studies are required to confirm this.

\section{Endotracheal tube}

Novel designs of ETTs target two major mechanisms of VAP, namely, microaspiration and biofilm formation. ${ }^{32,33}$ Microaspiration is controlled by incorporating changes in cuff shape, material, and addition of a subglottic suction port. Prevention of biofilm formation is managed by addition of coating, surface modification, and removal of biofilm by mechanical means. The conventional ETT cuff (eg Portex; Smiths Medical International Ltd, Ashford, UK) is made of polyvinyl chloride (PVC), of which, when inflated, redundant parts fold on themselves and, because of the thickness of the material $(>50 \mu)$, microchannels form through which leakage is possible. By modification of the shape from conical to tapered (eg TaperGuard; Covidien, Irvine [CA], US), better contact of the cuff with the trachea can be achieved, and microchannel formation is reduced. By modification of the material from PVC to the thin 7- $\mu$ thick polyurethane (eg Microcuff; Kimberly-Clark Health Care, Roswell [GA], US), microchannel formation can almost be prevented. Our benchtop study showed that the Microcuff consistently outperformed the Portex and the TaperGuard in terms of leakage, especially during zero PEEP mechanical ventilation, laboured breathing, disconnection, and airway suction..$^{34}$ One disadvantage of the Microcuff is that the material is so thin that even moisture diffuses across, leading to fluid accumulation inside the cuff with resultant blockage of the pilot balloon tube. This can be solved by purging the tube with small amount of air. Other materials being studied are Lycra fibre (Invista, Wichita [KS], US), silicone, and latex. Addition of a subglottic suction drainage (SSD) port removes secretions collected above the cuff (eg TaperGuard Evac, Covidien). In a meta-analysis of 10 RCTs with 2213 patients, SSD significantly reduced the incidence of VAP and early-onset VAP, shortened ventilation duration by 1.55 days, and prolonged time to VAP by 3.90 days. ${ }^{35}$ Ports of SSD are now available in tracheostomy tubes. One study of such tracheostomy tubes showed that the prevalences of VAP were $56 \%$ in the control group and $11 \%$ in the suction tracheostomy group. ${ }^{36}$ The SSD port can be put into intermittent or continuous suction, with similar efficacy of VAP prevention. However, the port could become blocked secondary to suctioned tracheal mucosa in one third of cases, with the possibility of tracheal injury.

Of the various coatings of ETT studied, so far, only silver-based coating (eg Agento IC; Bard Medical, Covington [GA], US) has been tested in clinical trials. A meta-analysis identified two high-quality RCTs with a total of 1630 participants, and showed that compared with non-coated ETTs, silver-coated ETTs resulted in a lower incidence of VAP, devicerelated adverse events, and microbiological burden, with no significant difference in total mortality. ${ }^{37}$ Recently, an ETT with a newly engineered micropattern surface was found to reduce colonisation and biofilm formation of key VAP-associated pathogens in vitro by $99.9 \%$ compared with unpatterned control ETTs, including methicillin-resistant $S$ aureus and $P$ aeruginosa biofilm formation. ${ }^{38}$ Another modification of the ETT is by addition of mucus slurping holes near the distal end of the ETT to keep the inner walls of the ETT free of mucus deposits. Attempts are also being made to develop mechanical means of removing adherent ETT secretions (eg endOclear catheter; endOclear LLC, Petoskey [MI], US), which could even relieve life-threatening ETT obstruction. Another example of mechanical removal is the Mucus Shaver. ${ }^{39}$

\section{Airway pressure}

Maintenance of a positive pressure gradient across the ETT cuff is an important factor to prevent secretions collecting above the cuff to trickle down across the cuff-trachea interface due to gravity. This pressure gradient is positive during positive pressure ventilation, but becomes zero during airway disconnection, and periodically negative during laboured inspiration through a narrow ETT or during airway suction. Without positive pressure, leakage around the cuff is significant, especially if the conventional PVC cuff is used and the cuff pressure is less than $30 \mathrm{~cm} \mathrm{H}_{2} \mathrm{O}^{34}$ During routine care, disconnections of the airway circuit are frequent, for instance, use of another ventilator for patient transport, change of the heat-and-moisture exchanger, spontaneous breathing trials, and change of ventilator tubing. Such disconnections should be avoided as far as possible. Spontaneous breathing trials should not be unduly prolonged without the intention for resumption of positive pressure ventilation or direct extubation. There is no evidence that the two methods of humidification, namely, using either a heated humidifier or a heat-andmoisture exchanger, affect the VAP rate.

\section{Cuff pressure}

A polyurethane cuff allows for a much lower sealing pressure than the conventional PVC cuff. ${ }^{34}$ Periodical manual checking of cuff pressure maintains adequate cuff pressure, but the benefit could be offset if the cuff pressure is accidentally released during checking. 
To overcome this issue, a continuous cuff pressure maintenance device can be used (Fig). A disposable device called the TRACOE Smart Cuff Manager (TRACOE Medical GmbH, Nieder-Olm, Germany; Fig) can also provide the similar functions of being both a pressure maintenance device (at $30 \mathrm{~cm}$ $\mathrm{H}_{2} \mathrm{O}$ ) and a visual indicator of the adequacy of cuff pressure. In the largest study to date on the incidence of VAP comparing a continuous and an intermittent cuff pressure control system on 284 patients, a lower incidence of VAP was found (22.0\% vs $11.2 \%){ }^{40}$

\section{Selective digestive decontamination, selective oropharyngeal decontamination, and probiotic or early antibiotic treatment}

Most meta-analyses have shown reductions in VAP with the use of selective digestive decontamination or selective oropharyngeal decontamination, but these interventions are still not being widely implemented because of concerns of emergence of antimicrobial resistance in pathogens. A recent systematic review of 64 studies suggested that such perceived risk of long-term harm could not be justified by the available data, but admitted that the effect on ICU-level antimicrobial resistance rates was understudied ${ }^{41}$ Further studies are also required for the use of probiotics regarding efficacy and the risk of colonisation or infection with probiotics. Around $10 \%$ to $30 \%$ of ventilator-associated tracheobronchitis may progress to VAP, and appropriate antibiotic treatment was independently associated with reduced risk for transition. ${ }^{42}$ For antibiotic prophylaxis, a prospective cohort study of 129 comatose patients (Glasgow Coma Score $\leq 8)$ showed that a single dose of antibiotic within 4 hours of intubation might lower the incidence of early-onset VAP, with no difference in late-onset VAP. ${ }^{43}$ Further RCTs are needed.

\section{Administrative strategies and coordination}

Good administrative strategies and coordination are especially important for the implementation of

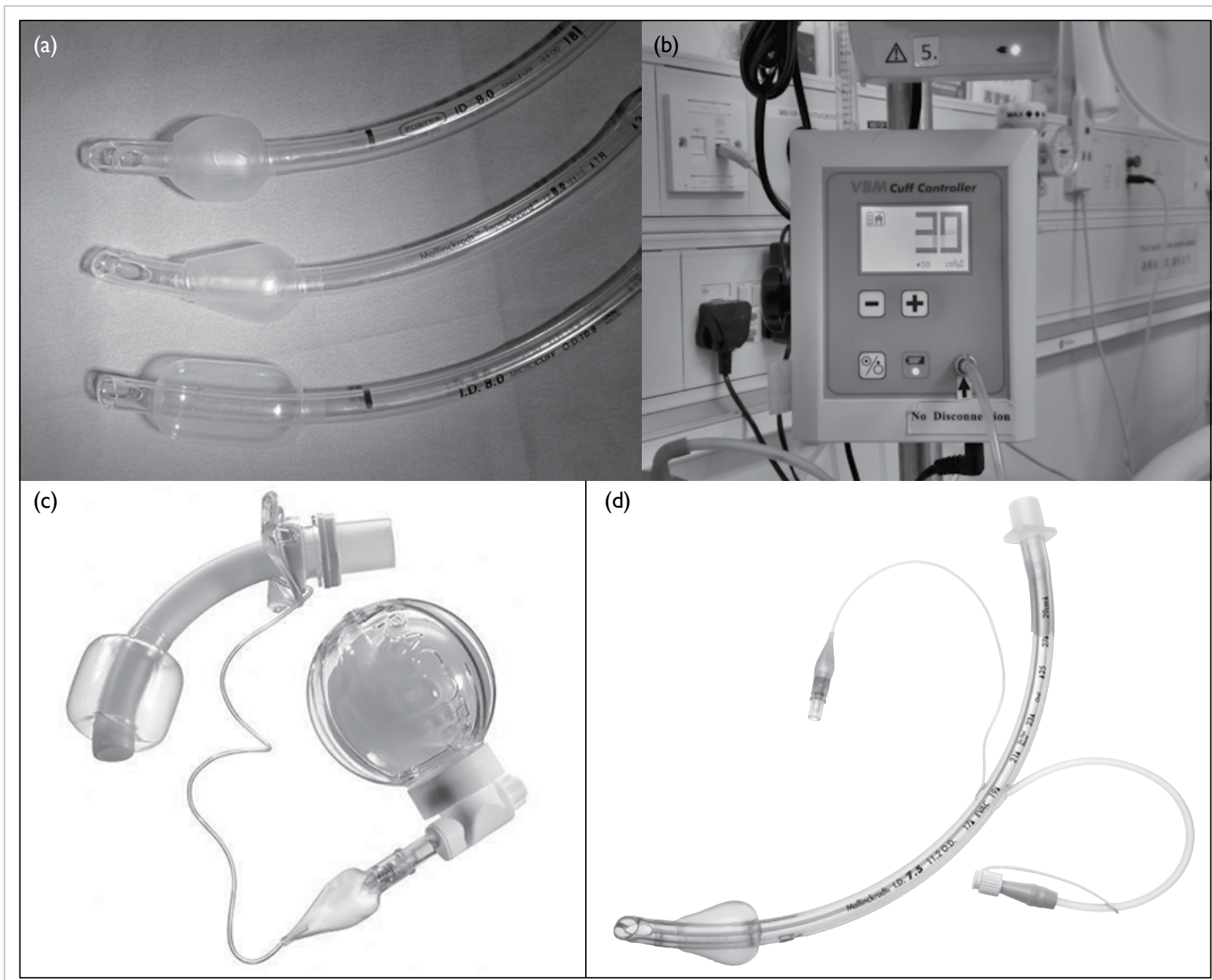

FIG. Devices for ventilator-associated pneumonia prevention

(a) Endotracheal tubes, from top to bottom - conventional Portex (polyvinyl chloride material), TaperGuard (with taper-shaped cuff), and Microcuff (with polyurethane cuff); (b) automated cuff pressure maintenance device; (c) the TRACOE Smart Cuff Manager; and (d) TaperGuard Evac - taper-shaped cuff with subglottic secretion drainage port 
this bundle of strategies all the way from patient care, equipment, infection control, and antibiotic stewardship. Considering the situation in Hong Kong that mechanically ventilated patients are being looked after not only in the ICU, but also in various critical care areas such as high dependency units, respiratory wards, and even general wards, it is imperative that a VAP protocol is in place and diligently adhered to in every such unit, with regular audits to ensure compliance. The existence of written standards for management of mechanically ventilated patients and the availability of VAP surveillance systems were positively associated with compliance with VAP-prevention measures and should be fostered at a policy level. ${ }^{44}$ Costeffectiveness data for the whole Ventilator Bundle are scarce and such analysis should be performed in future research. In one Danish cost-effectiveness analysis, implementation of the Ventilator Bundle was found to be potentially cost-effective from the perspective of the hospital, using outcomes of prevention of VAP and prevention of death. ${ }^{45}$ In view of the necessity for multidisciplinary involvement, VAP surveillance is better coordinated at a higher administrative level. The Hong Kong East Cluster of Hospitals has established a Task Force on Prevention of VAP in Critical Care Areas since 2013. Ventilatorassociated pneumonia should also be seriously considered as a key performance indicator in Hong Kong ICUs, as in other advanced countries.

\section{Conclusion}

Ventilator-associated pneumonia is the commonest, yet mostly preventable, cause of morbidity and mortality in mechanically ventilated patients. Successful control of VAP can save total hospitalisation cost, and is possible by using a multidisciplinary clinical and administrative approach. All units taking care of mechanically ventilated patients should have a VAP-prevention protocol in place, and VAP should be seriously considered to become a key performance indicator in local ICUs.

\section{References}

1. Melsen WG, Rovers MM, Groenwold RH, et al. Attributable mortality of ventilator-associated pneumonia: a meta-analysis of individual patient data from randomised prevention studies. Lancet Infect Dis 2013;13:665-71.

2. Lambert ML, Silversmit G, Savey A, et al. Preventable proportion of severe infections acquired in intensive care units: case-mix adjusted estimations from patientbased surveillance data. Infect Control Hosp Epidemiol 2014;35:494-501.

3. Ventilator-associated pneumonia (VAP). Available from: http://www.cdc.gov/hai/vap/vap.html. Accessed 21 Jul 2014.

4. Kalanuria AA, Zai W, Mirski M. Ventilator-associated pneumonia in the ICU. Crit Care 2014;18:208.

5. Fàbregas N, Ewig S, Torres A, et al. Clinical diagnosis of ventilator associated pneumonia revisited: comparative validation using immediate post-mortem lung biopsies. Thorax 1999;54:867-73.

6. Berton DC, Kalil AC, Teixeira PJ. Quantitative versus qualitative cultures of respiratory secretions for clinical outcomes in patients with ventilator-associated pneumonia. Cochrane Database Syst Rev 2012;(10):CD006482.

7. Koulenti D, Lisboa T, Brun-Buisson C, et al. Spectrum of practice in the diagnosis of nosocomial pneumonia in patients requiring mechanical ventilation in European intensive care units. Crit Care Med 2009;37:2360-8.

8. Novosel TJ, Hodge LA, Weireter LJ, et al. Ventilatorassociated pneumonia: depends on your definition. Am Surg 2012;78:851-4.

9. Klompas M. Interobserver variability in ventilatorassociated pneumonia surveillance. Am J Infect Control 2010;38:237-9.

10. American Thoracic Society; Infectious Diseases Society of America. Guidelines for the management of adults with hospital-acquired, ventilator-associated, and healthcareassociated pneumonia. Am J Respir Crit Care Med 2005;171:388-416.

11. Ventilator-Associated Event (VAE). Available from: http:// www.cdc.gov/nhsn/PDFs/pscManual/10-VAE_FINAL. pdf. Accessed 1 Jan 2015.

12. Muscedere J, Sinuff T, Heyland DK, et al. The clinical impact and preventability of ventilator-associated conditions in critically ill patients who are mechanically ventilated. Chest 2013;144:1453-60.

13. Bahrani-Mougeot FK, Paster BJ, Coleman S, et al. Molecular analysis of oral and respiratory bacterial species associated with ventilator-associated pneumonia. J Clin Microbiol 2007;45:1588-93.

14. Charles MP, Easow JM, Joseph NM, Ravishankar M, Kumar S, Sivaraman U. Aetiological agents of ventilatorassociated pneumonia and its resistance pattern-a threat for treatment. Australas Med J 2013;6:430-4.

15. How-to guide: Prevent ventilator-associated pneumonia. Available from: http://www.ihi.org/resources/Pages/Tools/ HowtoGuidePreventVAP.aspx. Accessed 20 Jul 2014.

16. Khorvash F, Abbasi S, Meidani M, Dehdashti F, Ataei B. The comparison between proton pump inhibitors and sucralfate in incidence of ventilator associated pneumonia in critically ill patients. Adv Biomed Res 2014;3:52.

17. Recommendations on prevention of ventilator-associated pneumonia. Scientific Committee on Infection Control, and Infection Control Branch, Centre for Health Protection, Department of Health; 2010.

18. Long MN, Wickstrom G, Grimes A, Benton CF, Belcher B, Stamm AM. Prospective, randomized study of ventilatorassociated pneumonia in patients with one versus three ventilator circuit changes per week. Infect Control Hosp Epidemiol 1996;17:14-9.

19. Fink JB, Krause SA, Barrett L, Schaaff D, Alex CG. Extending ventilator circuit change interval beyond 2 days reduces the likelihood of ventilator-associated pneumonia. Chest 1998;113:405-11.

20. Martínez-Reséndez MF, Garza-González E, MendozaOlazaran S, et al. Impact of daily chlorhexidine baths and hand hygiene compliance on nosocomial infection rates in critically ill patients. Am J Infect Control 2014;42:713- 
21. Drakulovic MB, Torres A, Bauer TT, Nicolas JM, Nogué S, Ferrer M. Supine body position as a risk factor for nosocomial pneumonia in mechanically ventilated patients: a randomised trial. Lancet 1999;354:1851-8.

22. The Gravity VAP network. Gravity VAP-Trial. Available from: http://compartint.net/gravityvaptrial/joomla/. Accessed 21 Jul 2014.

23. Staudinger T, Bojic A, Holzinger U, et al. Continuous lateral rotation therapy to prevent ventilator-associated pneumonia. Crit Care Med 2010;38:486-90.

24. Burns KE, Meade MO, Premji A, Adhikari NK. Noninvasive positive-pressure ventilation as a weaning strategy for intubated adults with respiratory failure. Cochrane Database Syst Rev 2013;(12):CD004127.

25. Kress JP, Pohlman AS, O'Connor MF, Hall JB. Daily interruption of sedative infusions in critically ill patients undergoing mechanical ventilation. $\mathrm{N}$ Engl $\mathrm{J}$ Med 2000;342:1471-7.

26. Girard TD, Kress JP, Fuchs BD, et al. Efficacy and safety of a paired sedation and ventilator weaning protocol for mechanically ventilated patients in intensive care (Awakening and Breathing Controlled trial): a randomised controlled trial. Lancet 2008;371:126-34.

27. Quenot JP, Ladoire S, Devoucoux F, et al. Effect of a nurse-implemented sedation protocol on the incidence of ventilator-associated pneumonia. Crit Care Med 2007;35:2031-6.

28. Shi Z, Xie H, Wang P, et al. Oral hygiene care for critically ill patients to prevent ventilator-associated pneumonia. Cochrane Database Syst Rev 2013;(8):CD008367.

29. Seguin P, Laviolle B, Dahyot-Fizelier C, et al. Effect of oropharyngeal povidone-iodine preventive oral care on ventilator-associated pneumonia in severely braininjured or cerebral hemorrhage patients: a multicenter, randomized controlled trial. Crit Care Med 2014;42:1-8.

30. Chow MC, Kwok SM, Luk HW, Law JW, Leung BP. Effect of continuous oral suctioning on the development of ventilator-associated pneumonia: a pilot randomized controlled trial. Int J Nurs Stud 2012;49:1333-41.

31. Reignier J, Mercier E, Le Gouge A, et al. Effect of not monitoring residual gastric volume on risk of ventilatorassociated pneumonia in adults receiving mechanical ventilation and early enteral feeding: a randomized controlled trial. JAMA 2013;309:249-56.

32. Fernandez JF, Levine SM, Restrepo MI. Technologic advances in endotracheal tubes for prevention of ventilatorassociated pneumonia. Chest 2012;142:231-8.

33. Lam SM, Lau AC. Prevention of ventilator-associated pneumonia (VAP) by novel endotracheal tube designs. Hong Kong Lung Foundation, Hong Kong Thoracic Society
\& ACCP (HK \& Macau Chapter) Newsletter 2011: 32-5.

34. Lau AC, Lam SM, Yan WW. Benchtop study of leakages across the Portex, TaperGuard, and Microcuff endotracheal tubes under simulated clinical conditions. Hong Kong Med J 2014;20:7-15.

35. Wang F, Bo L, Tang L, et al. Subglottic secretion drainage for preventing ventilator-associated pneumonia: an updated meta-analysis of randomized controlled trials. J Trauma Acute Care Surg 2012;72:1276-85.

36. Ledgerwood LG, Salgado MD, Black H, Yoneda K, Sievers A, Belafsky PC. Tracheotomy tubes with suction above the cuff reduce the rate of ventilator-associated pneumonia in intensive care unit patients. Ann Otol Rhinol Laryngol 2013;122:3-8.

37. Li X, Yuan Q, Wang L, Du L, Deng L. Silver-coated endotracheal tube versus non-coated endotracheal tube for preventing ventilator-associated pneumonia among adults: a systematic review of randomized controlled trials. J Evid Based Med 2012;5:25-30.

38. May RM, Hoffman MG, Sogo MJ, et al. Micro-patterned surfaces reduce bacterial colonization and biofilm formation in vitro: potential for enhancing endotracheal tube designs. Clin Transl Med 2014;3:8.

39. Berra L, Coppadoro A, Bittner EA, et al. A clinical assessment of the Mucus Shaver: a device to keep the endotracheal tube free from secretions. Crit Care Med 2012;40:119-24.

40. Lorente L, Lecuona M, Jiménez A, et al. Continuous endotracheal tube cuff pressure control system protects against ventilator-associated pneumonia. Crit Care 2014;18:R77.

41. Daneman N, Sarwar S, Fowler RA, Cuthbertson BH; SuDDICU Canadian Study Group. Effect of selective decontamination on antimicrobial resistance in intensive care units: a systematic review and meta-analysis. Lancet Infect Dis 2013;13:328-41.

42. Nseir S, Martin-Loeches I, Makris D, et al. Impact of appropriate antimicrobial treatment on transition from ventilator-associated tracheobronchitis to ventilatorassociated pneumonia. Crit Care 2014;18:R129.

43. Vallés J, Peredo R, Burgueño MJ, et al. Efficacy of singledose antibiotic against early-onset pneumonia in comatose patients who are ventilated. Chest 2013;143:1219-25.

44. Kaier K, Lambert ML, Frank UK, et al. Impact of availability of guidelines and active surveillance in reducing the incidence of ventilator-associated pneumonia in Europe and worldwide. BMC Infect Dis 2014;14:199.

45. Møller AH, Hansen L, Jensen MS, Ehlers LH. A costeffectiveness analysis of reducing ventilator-associated pneumonia at a Danish ICU with ventilator bundle. J Med Econ 2012;15:285-92. 